\section{A construção referencial em compósitos de gêneros na mídia Facebook}

The reference construction in composites of genres on

Mônica Magalhães CAVALCANTE (UFC)

monicamco2@gmail.com

Isabel MUNIZ-LIMA (UFC/UNL) isabelmunizlima@gmail.com

Recebido em: 06 de fev. de 2021. Aceito em: 12 de set. de 2021.

\title{
00000000000
}

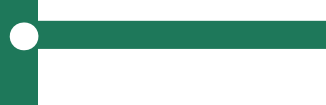

CAVALCANTE,

MUNIZ-LIMA

Mônica Magalhães;

Isabel. A construção referencial em compósitos de gêneros na mídia Facebook. Entrepalavras, Fortaleza, v. 11, n. 3, e2328, p. 430-450, set.-dez./2021. DOI: 10.22168/22376321-32328

Resumo: Este artigo busca investigar a construção referencial em textos que circulam em páginas do Facebook. Nesta investigação, defendemos que os textos dessa mídia se apresentam em um compósito de gêneros e que a construção referencial deve ser observada tendo em vista esse agrupamento. O presente estudo se vincula à perspectiva da Linguística Textual praticada no Brasil, sobretudo em investigações do grupo de pesquisa Protexto, da Universidade Federal do Ceará, e tem como base pesquisas recentes no âmbito da referenciação (CAVALCANTE, 2011; CUSTÓDIO-FILHO, 2011; CAVALCANTE; BRITO, 2016; MATOS, 2018). Para esta análise, selecionamos postagem publicada na página do Facebook do jornal O Povo, em 27 de novembro de 2020, sobre um pronunciamento do presidente brasileiro Jair Messias Bolsonaro, em relação à Covid-19. Este trabalho nos permitiu perceber que a (re) elaboração do referente "Covid-19" exige que o leitor se reporte a âncoras dadas não só na postagem principal do jornal, mas também em outros elementos desse compósito, como nos comentários.

Palavras-chave: Referenciação.

Compósito de gêneros. Mídia Facebook. 
Abstract: This paper seeks to investigate the reference construction in texts that circulate on Facebook pages. In this investigation, we defend that the texts of this media are presented in a composite of genres and that the referential construction should be observed in view of this grouping. This study is linked to the perspective of Textual Linguistics practiced in Brazil, especially in investigations by the Protexto research group of the Federal University of Ceará, and is based on recent research in the field of referencing (CAVALCANTE, 2011, CUSTÓDIO-FILHO, 2011; CAVALCANTE \& BRITO, 2016; MATOS, 2018). For this analysis, we selected a post published on the Facebook page of the newspaper O Povo on November 27, 2020 on a statement by Brazilian President Jair Bolsonaro regarding Covid-19. This work allowed us to realize that the (re)elaboration of the referent "Covid-19" requires the reader to report to anchors given not only in the main post of the newspaper, but also in other elements of this composite, such as comments.

Keywords: Reference. Composite of genres. Facebook Media.

\section{Introdução}

A referenciação tem se mostrado categoria produtiva nos estudos do texto empreendidos pela Linguística Textual. Esse fenômeno, complexo e dinâmico, pode ganhar ainda múltiplos olhares quando considerado em modos de interação digital, como as postagens manifestadas em páginas de jornais na mídia Facebook.

Custódio Filho (2011) já sinalizava para a importância de se investigar a referenciação em contextos mais diversificados do que os mais tradicionais empreendidos no início dos estudos desse fenômeno. Em sua tese, o pesquisador menciona que outros estímulos, além do verbal, contribuem na produção de sentido. O pesquisador traz uma relevante contribuição para a Linguística Textual ao investigar a referenciação em interações que envolvem textos longos, como o que se apresenta nas crônicas; e em interações que envolvem texto verbal e imagens dinâmicas, como o caso das séries cinematográficas.

Alguns trabalhos no âmbito da referenciação procuraram investigar textos que se manifestam por meio de distintas interações e, com essa iniciativa, demonstraram um destacado avanço no estudo do fenômeno da construção referencial. Nascimento (2014), por exemplo, analisou a construção de referentes em interações que envolvem o aspecto verbo-audiovisual. A pesquisadora investigou de que maneira recursos multimodais contribuem para a construção de referentes no curta-metragem Vida Maria e constatou que a consideração conjunta da saliência e do enquadramento de sistemas visuais pode se apresentar como um recurso eficaz na ativação dos referentes na memória discursiva dos leitores. A partir da análise do corpus, a autora constatou 
V. 11 (3)

$430-450$ set-dez 2021

que elementos multissemióticos (cores, expressões faciais, mudança de cenário, planos, saliência, enquadramento) foram relevantes para a construção das redes referenciais.

O trabalho de Lima (2009) também reforça a necessidade de que sejam investigadas novas configurações textuais e, visando a esse objetivo, a autora analisou a construção de referentes por meio de imagens estáticas, dando destaque para o modo como aspectos não verbais participam de processos de encapsulamento. No que concerne a interações que implicam recursos, como a mídia internet, temos o trabalho de Simas (2015), que analisou a construção de referentes em fóruns de Educação a Distância (doravante $\mathrm{EAD}$ ). Ao comparar os fóruns $\mathrm{EAD}$ com os gêneros orais, o autor buscou realizar uma interface entre fala e escrita.

De acordo com Custódio-Filho (2011), analisar textos em distintas interações pode contribuir para que sejam caracterizados processos referenciais ainda não investigados na tradição dos estudos em Linguística Textual. Igualmente, partilhamos essa visão e, nessa perspectiva, propomos, neste artigo, analisar a influência da disposição compósita de textos na mídia Facebook sobre as etapas de construção dos processos referenciais.

Para cumprir esse objetivo, selecionamos um compósito de textos da página do Facebook do jornal 0 Povo, de 27 de novembro de 2020, e analisamos como o referente "coronavírus" é (re)elaborado nesse conjunto textual. Inicialmente, apresentamos o referencial teórico que guia esta análise; em seguida, os aspectos metodológicos; a análise dos textos e, por fim, algumas discussões sobre esta investigação.

\section{A noção de texto que adotamos e a questão do compósito}

Devido à complexidade do texto como objeto de investigação, a Linguística Textual (doravante LT) tem revisitado conceitos decisivos para a análise da textualização. Antes considerada apenas na perspectiva do verbal, hoje a noção de texto se amplia:

A investigação dos processos que concorrem para a produção e compreensão de um texto - entendido como enunciado completo, que se conclui como unidade de comunicação e que é reconhecível por sua unidade de sentido em contexto - demanda um tratamento específico, que não se limita ao componente gramatical ou linguístico dos enunciados efetivamente produzidos (embora, obviamente, o aparato linguístico também seja considerado). (CAVALCANTE et al., 2019, p. 28). 
A concepção de texto da LT praticada no Brasil, sobretudo em estudos do grupo de pesquisa Protexto, envolve uma unidade de coerência em contexto, construída e negociada em um modo de interação. O texto, portanto, será tratado neste artigo como um enunciado que acontece como evento singular, único a cada vez, compondo, assim, uma unidade de comunicação e de sentido, sempre em contexto, e expressa por uma combinação de sistemas semióticos (CAVALCANTE et al., 2019). Defendemos, com Cavalcante e Martins (2020), que essa unidade inicia e acaba:

[...] por entendermos o texto como enunciado completo, que se conclui como unidade de comunicação e que é reconhecível por sua unidade de sentido em contexto, existe um limite para ele. Esse limite é estabelecido pela própria interação simulada, que, em determinado tempo-espaço, termina por findar. (CAVALCANTE; MARTINS, 2020, p. 247).

Essa evolução da perspectiva dada ao objeto de estudo da Linguística Textual leva, consequentemente, à necessidade de revisão de outros conceitos básicos, como as noções de gênero, suporte, mídia e interação ${ }^{1}$. Devido ao recorte deste artigo, preferimos nos deter apenas em apresentar uma reflexão sobre as consequências de se observar o texto e o gênero em modos de interação digital on-line na página do jornal o Povo na mídia Facebook.

No início dos anos 2000, com o advento da web 2.0 e das redes sociais, a avalanche de textos que surge nas mídias digitais como os perfis de Facebook, as conversas via Whatsapp ou via Messenger, os comentários em blogs, as entrevistas em formato podcast, além de outros textos -, para Bonini (2011) e Lima (2013), extrapola o conceito de gênero e adentra o universo dos hipergêneros. Segundo Bonini (2011), os hipergêneros correspondem a um "agrupamento de gêneros para compor uma unidade maior" (p. 681) ou a "um gênero formado por outros gêneros" (p. 682). Embora não se debruce detalhadamente sobre esse conceito, Bonini (2011) afirma:

[...] os gêneros, por vezes, são produzidos em agrupamento, compondo uma unidade de interação maior (um grande enunciado) que estou chamando de hipergênero. O jornal, nesse sentido, é um hipergênero, uma vez que ele responde às características propostas por Bakhtin (1953) para caracterizar o enunciado [...]. Uma notícia é produzida em um jornal como parte de um grande enunciado, de modo que ela se

${ }^{1}$ Essa discussão tem sido aprofundada na tese de doutoramento (em andamento) de Isabel Muniz Lima. 
V. 11 (3)

$430-450$ set-dez

2021

relaciona necessariamente com os demais gêneros produzidos (como a chamada, com o editorial, com os artigos etc.). Todo hipergênero, como o jornal, a revista, o site, apresenta um sistema de disposição dos enunciados que envolve gêneros organizadores (sumário, introdução, editorial, chamada, etc.) e gêneros de funcionamento (notícia, romance, tratado, revista, etc.). (BONINI, 2011, p. 692).

Alguns pontos devem ser examinados cuidadosamente nessa definição. A proposta de Bonini (2011) é que se considere um termo específico a ser empregado nas situações em que há um conjunto de gêneros discursivos reunidos de modo a compor uma unidade. Que os gêneros desse conjunto podem compor uma só unidade de interação maior, não temos dúvida: é o que encontramos, por exemplo, no compósito de uma nota jornalística em um blog, junto aos comentários atinentes a ela. Mas nem sempre os comentários engatilhados por tal nota jornalística se mantêm na mesma interação, porque, quando os participantes mudam de tópico, por vezes, se inicia um novo texto com outros interactantes, em outra interação particular, mais dirigida.

Outro ponto a ser salientado é que não nos parece apropriado tratar o hipergênero como um "grande enunciado", tendo em vista, exatamente, as concepções bakhtinianas de enunciado e de gênero do discurso. Para nós, se os gêneros são tipos de enunciado relativamente estáveis, então os enunciados devem equivaler a textos, e os gêneros a "tipos" de texto relativamente estáveis. Se um texto corresponde sempre a um gênero, não caberia falar de mais de um texto e um mesmo gênero, ainda que elastecido e complexificado. Pensamos que esses agrupamentos componham uma unidade de análise acima do gênero, comportando mais de um texto (e mais de um gênero), reunidos em um suporte que os integra.

Assim sendo, neste trabalho, não tomaremos a acepção do autor de que o hipergênero seria um "um grande enunciado", tendo em vista que essa aceitação iria de encontro ao que temos concebido hoje na LT como texto. Porém, concordamos que os hipergêneros parecem funcionar como um compósito de gêneros que se relacionam entre si. Por isso, preferimos, neste artigo, utilizar a expressão "compósito de gêneros" para enfatizar a ideia de agrupamento de textos mencionada pelo autor. Assumimos esses agrupamentos como compósitos, porque supomos estar diante de diversificadas possibilidades de reunião de gêneros em um mesmo espaço físico de atualização de textos. Além disso, consideraremos gêneros como "entidades sociodiscursivas e 
formas de ação social incontornáveis de qualquer situação comunicativa" (MARCUSCHI, 2008, p. 19), ou seja, como padrões textuais e discursivos ${ }^{2}$ socialmente reconhecidos.

Como todo texto se realiza em um gênero (MARCUSCHI, 2008), admitimos que, em situações de interação como as que ocorrem nas páginas de perfis do Facebook, estamos diante de um compósito de gêneros, os quais se atualizam em conjunto num mesmo suporte. Esta é a ideia que tem sido defendida também por Carvalho (2020). No exemplo a seguir, observemos como se manifesta esse agrupamento de gêneros:

Exemplo 1 - Cópias de tela de postagem de 27 de novembro de 2020 na página do jornal o Povo no Facebook
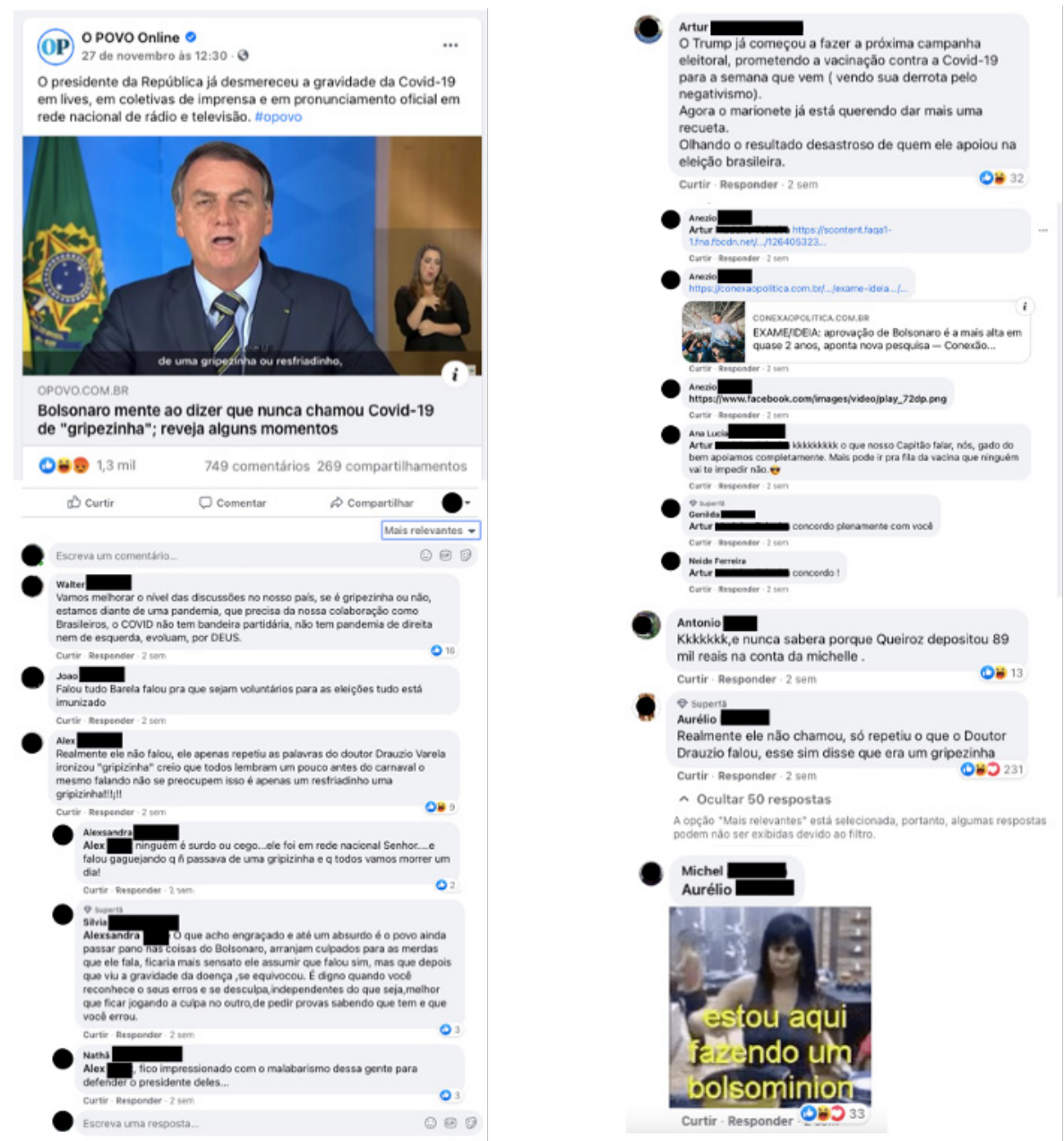

Fonte: Postagem no Facebook do jornal O Povo de 27 de novembro de $2020^{3}$.

\footnotetext{
${ }^{2}$ O grupo Protexto assume que há uma relação simbiótica entre texto e discurso. Fruto das relações da formação discursiva em que está inserido, o discurso também é estabelecido no plano textual. Uma análise em LT nunca é apenas microlinguística, mas é uma análise, como propõe Adam (2019), em três níveis: microlinguística (da ordem do gramatical, da realização de determinadas formas linguísticas), mesolinguística (da ordem do plano do texto, da composição) e macrolinguística (da ordem da relação com os gêneros e com os discursos).
}

3 Disponível em: https://www.facebook.com/OPOVOOnline/posts/3723712540999377. 
V. 11 (3)

$430-450$ set-dez 2021

Nesse compósito, agrupam-se os seguintes gêneros: a postagem principal do jornal O Povo, cuja manchete diz "Bolsonaro mente ao dizer que nunca chamou Covid-19 de 'gripezinha', reveja alguns momentos". O jornal, como um "hipergênero", apresenta uma manchete, configura-se pelo nome do jornal "O Povo Online", pela data, pela informação em cima da imagem, pela imagem do presidente na manchete e por outros recursos técnicos, como os hiperlinks disponíveis ao clicarmos no nome do jornal ou na manchete, por exemplo. Consideramos, ainda, que as reações, os compartilhamentos, o contador de curtidas e os comentários estão previstos no lócus desse compósito e que constituem outros gêneros, porque preveem uma outra interação, e até mais de uma.

Admitir a existência de uma unidade maior que a do gênero, que pode até ser bastante diversa em termos de agrupamentos diferenciados, é abrir a possibilidade de inúmeras relações de um texto com outros num mesmo compósito, e a dos processos referenciais é uma delas.

Em consequência dessa forma de organização dos textos nas páginas de perfil do Facebook, defendemos que os referentes também podem se relacionar tendo em vista esse compósito. Antes de detalharmos essa questão central, precisamos nos situar teoricamente quanto ao fenômeno da referenciação.

\section{A abordagem da LT para o fenômeno da referenciação}

Esta seção tem como objetivo situar os estudos sobre referenciação no atual cenário da Linguística Textual e enfatizar a necessidade de se ampliar os contextos de investigação da referenciação, particularmente levando em consideração os modos de interação digital on-line.

Cavalcante (2011) e Custódio-Filho (2011) apresentam um breve panorama dos estudos sobre referenciação desenvolvidos até o ano de publicação de suas obras e os dividem em duas tendências. Segundo Custódio-Filho (2011), os estudos da primeira tendência estavam mais voltados para a descrição e análise dos processos referenciais:

Nessa fase, a elaboração de propostas classificatórias para as diversas formas e estratégias de referenciação, além de propor quadros descritivos, tinha a intenção de orientar a operacionalização para o tratamento metodológico de outras pesquisas na área. Além dessas pesquisas de cunho mais geral, 
há aquelas que se preocupam em analisar um tipo específico de construção referencial, como a anáfora indireta, a anáfora recategorizadora, o encapsulamento (incluindo a rotulação metadiscursiva) e o dêitico referencial. Em muitos desses estudos, também se vê a preocupação em propor tipologias. (CUSTÓDIO-FILHO, 2011, p. 13).

Essas investigações foram essenciais para a evolução das pesquisas sobre o fenômeno da referenciação e endossaram as reflexões em torno da noção de referente, ou, conforme preferem Mondada e Dubois (2003), em torno dos objetos de discurso. Os avanços em relação aos estudos do fenômeno da referenciação se deram a partir da compreensão de que seria preciso considerar um princípio fundamental nesse processo: a natureza sociocognitiva da referência. Portanto, além de dar importância à noção de que os objetos de discurso são fruto de constante (re)elaboração da realidade e de que esse processo é resultado de negociação ativa dos participantes, a LT passou a considerar, como pressuposto teórico fundamental da referenciação, a atividade cognitiva (CAVALCANTE; CUSTÓDIO-FILHO; BRITO, 2014, p. 27).

É preciso esclarecer, todavia, que os interesses da LT se limitam a tomar a atividade cognitiva apenas como pressuposto, o qual tem relação com a admissão de que os conhecimentos são negociados, construídos e compartilhados, o que "garante o caráter marcadamente dinâmico do processo" de referenciação (CAVALCANTE; CUSTÓDIO FILHO; BRITO, 2014, p. 41). Dessa forma, não cabe à LT a análise de modelos e esquemas mentais como objeto de investigação. Conforme assinalam Cavalcante, Custódio Filho e Brito (2014), é possível recuperar recategorizações por meio da ativação de conhecimentos prévios, originados da mente do interlocutor. Essa ponderação deu impulso aos estudos sobre o fenômeno da referenciação, a qual passou a ser tomada como "uma construção sociocognitivo-discursiva de objetos de discurso reveladores de versões da realidade e estabelecidos mediante processos de negociação" (p. 42).

Nessa perspectiva, os estudos da segunda tendência passaram a defender os objetos de discurso como "construção cognitivo-discursiva que, mesmo quando não se explicita no cotexto por meio de uma expressão linguística, constitui ainda um dos processos referenciais" (CAVALCANTE, 2011, p. 11). Assim, esses estudos passaram a investigar a elaboração de referentes para além das expressões referenciais (CUSTÓDIO FILHO, 2011, p. 139). Segundo Cavalcante (2011), nesse movimento, a LT tem procurado investir esforços na observação de 
V. 11 (3)

$430-450$ set-dez 2021

"[...] como os referentes, mesmo quando nem foram ainda designados no cotexto, já podem estar acessíveis no mundo do discurso, até irem, aos poucos, estabilizando-se e, em seguida, desestabilizando-se, num jogo de coconstrução" (p. 120).

As análises empreendidas por Custódio Filho (2011) enfatizam o caráter inovador da segunda tendência de estudos da referenciação. Em sua tese, o pesquisador investiga a participação de múltiplos fatores na elaboração cognitivo-discursiva dos objetos de discurso. Para tanto, o linguista considera o papel das imagens na construção da referência, as particularidades da referenciação em textos mais longos e/ou ininterruptos, além da construção de referentes em textos escritos e audiovisuais. A partir da análise empreendida em sua tese, Custódio Filho (2011) ressalta a possibilidade de a recategorização se manifestar de forma independente do domínio das expressões referenciais.

Nesse sentido, Cavalcante, Custódio-Filho e Brito (2014) mencionam que a análise da construção dos objetos de discurso deve se fazer por meio da consideração, não só de determinadas expressões referenciais, mas também das pistas multimodais e dos fatores contextuais - escolhas que visam orientar a interpretação que o interlocutor fará dos referentes.

Neste artigo, defendemos que, em certos contextos digitais on-line, como nas páginas de perfil no Facebook, é preciso observar como a disposição em compósito de textos intervêm nas etapas de construção referencial. Para verificar essa hipótese, propomos investigar de que modo se apresentam os processos básicos de (re)elaboração, propostos em Custódio-Filho (2011) e reorientados em Cavalcante e Brito (2016) e Matos (2018), em uma postagem realizada na página de Facebook do jornal O Povo.

As etapas de (re)elaboração dos referentes

De acordo com Custódio-Filho (2011), dois processos básicos se manifestam na (re)elaboração dos referentes. O primeiro é o processo de apresentação, que diz respeito à maneira como um dos referentes escolhidos se manifesta na primeira vez em que aparece. O autor ratifica que esse processo ocorre uma única vez e é primordial para a concretização das funções dos demais processos.

O segundo processo básico de (re)elaboração dos referentes, de acordo com a proposta de Custódio-Filho (2011), é o processo de 
mudança. Nesse processo, estão incluídos todos os acréscimos feitos aos referentes. Segundo o autor, sua função é permitir que se revelem as modificações do referente ao longo do texto. O autor subdivide esse processo em três casos. O primeiro, a mudança por acréscimo, diz respeito aos casos em que são conferidas modificações ao referente, porém essas alterações não rompem a compreensão do que se sabia até então sobre ele:

Para cada um dos textos, temos elementos centrais que orientam a condição dos personagens. Esses elementos centrais, após apresentados, sofrem acréscimos que modificam sua situação inicial, mas que, diferentemente da correção, não promovem uma ruptura em relação à compreensão que até então tinha sido feita. (CUSTÓDIO-FILHO, 2011, p. 194).

O segundo caso de processo de mudança apresentado pelo autor é aquele em que ocorre uma correção. De acordo com o pesquisador, a mudança por correção consiste nos processos de alteração radicais que envolvem uma ruptura com o que se vinha construindo em relação ao referente. Nesses casos, há "transformações diretamente envolvidas no efeito de surpresa e/ou, eventualmente, nas mudanças no estatuto dos personagens as quais se orientam em sentido contrário ao que se vinha construindo até então" (CUSTÓDIO-FILHO, 2011, p. 194).

Por último, Custódio-Filho (2011) propõe o caso de mudança por confirmação. De acordo com o autor, essa situação está relacionada à retomada de algum traço anteriormente mencionado no texto. Conforme o linguista esclarece, trata-se "portanto, de uma etapa em que é mantido o que já foi assentado por reelaborações anteriores" (p. 195). Custódio-Filho (2011) acrescenta, ainda, que

[...]embora, inicialmente, pareça paradoxal considerar que uma confirmação implique uma mudança, é importante ter em mente que a confirmação quase nunca é apenas uma mera repetição de características, mas, sim, uma estratégia de destaques necessários. (CUSTÓDIO-FILHO, 2011, p. 195).

Com base, portanto, no que o autor propõe, sintetizamos os processos básicos de construção referencial no seguinte quadro: 
V. 11 (3)

$430-450$

set-dez

2021
Quadro 1 - Quadro-resumo dos processos básicos de construção referencial propostos por Custódio-Filho (2011)

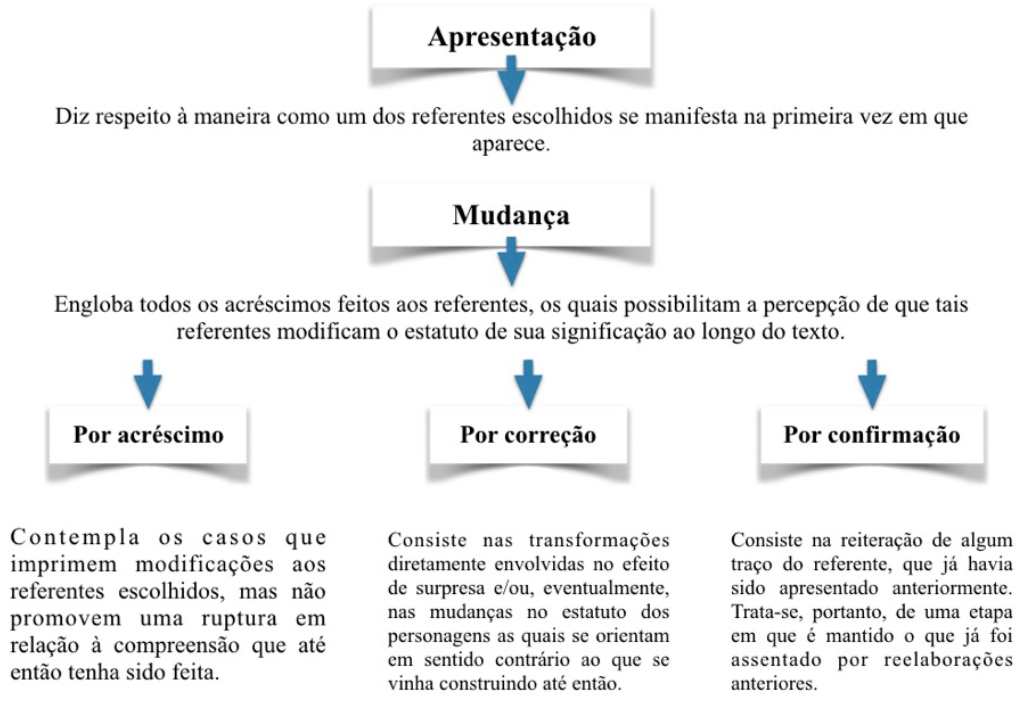

Fonte: elaborado pelas autoras com base em Custódio-Filho (2011).

A proposta de Custódio-Filho (2011) tem contribuído para pesquisas produtivas no campo da referenciação, dentre elas, as teses de doutoramento de Nascimento (2014), que investigou como os recursos multimodais colaboram para o processo de construção referencial proposto pelo pesquisador, e de Matos (2018), que utilizou essas etapas para observar as relações entre objetos de discurso e recategorização em notas jornalísticas.

Segundo Cavalcante e Brito (2016), o fenômeno da recategorização faz parte da própria natureza da retomada anafórica. Para as autoras, a recategorização é um processo de idas e vindas, em que o referente sofre, a todo momento, transformações. Essas retomadas constantes teriam a função de manter ou fazer progredir o referente no texto:

[...] o fenômeno da recategorização compõe a dinâmica natural de retomada anafórica, pela qual os referentes, ao mesmo tempo que se mantêm no texto por algum tipo de associação, também evoluem em diferentes proporções, em proveito da progressão temática. Assim, a recategorização não consiste em mais um tipo de processo referencial à moda da introdução, da anáfora e da dêixis, mas integra, isto sim, todas as retomadas anafóricas. (CAVALCANTE; BRITO, 2016, p. 119).

Nessa perspectiva, as autoras sugerem que as mudanças por acréscimo, por correção e por confirmação sejam todas consideradas 
como etapas possíveis de recategorização nas retomadas anafóricas. Por isso, pleiteiam que as recategorizações sejam entendidas como intrínsecas ao processo de transformação das anáforas:

Na esteira desse pensamento, seria redundante subespecificar que as mudanças se realizam por acréscimos (já que por "acréscimos" se entendem "alterações"), porque toda modificação implica a inserção de um novo viés. Por isso, substituímos a designação de "mudança" pela de recategorização, sem que seja necessário informar que ela se constrói por acréscimos. (CAVALCANTE; BRITO, 2016, p. 129).

As autoras propõem que os processos de apresentação e de retomada recategorizadora sejam compreendidos como funções excludentes dos processos referenciais. O processo de retomada recategorizadora teria, nesse caso, ou função de manutenção ou de progressão referencial:

Quadro 2 - Funções intrínsecas aos processos referenciais

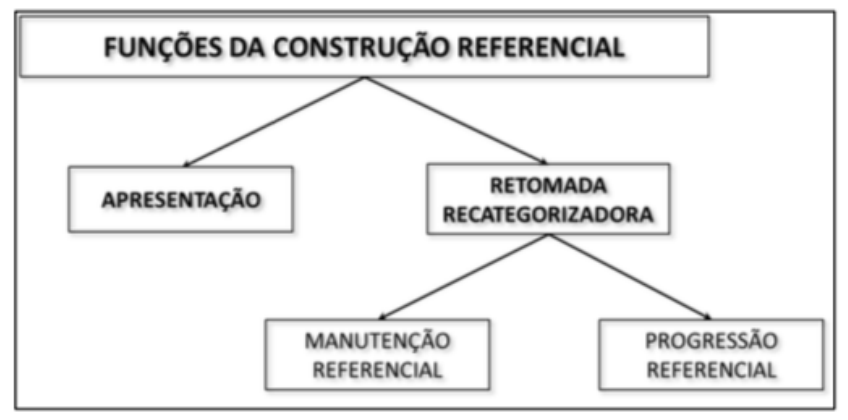

Fonte: Cavalcante e Brito (2016, p. 129).

Dessa forma, Cavalcante e Brito (2016) compreendem que as retomadas recategorizadoras são processos que tanto mantêm como fazem progredir os referentes. A proposta de Cavalcante e Brito (2016), ao realçar as funções específicas das anáforas - manutenção e progressão referencial -, contribui para uma ampliação do entendimento sobre a complexidade do fenômeno da referenciação.

Matos (2018) acrescenta a essas constatações que, em alguns casos de anáfora, certos traços do referente são modificados em sentido contrário ao que se vinha sendo apresentado. Ampliando as designações apresentadas por Custódio Filho (2011) e revisitadas em Cavalcante e Brito (2016), a autora sugere que sejam consideradas as recategorizações por desconfirmação. Matos (2018) esclarece que 
V. 11 (3)

$430-450$

set-dez

2021

[...] apesar de sugerirmos que a recategorização pode ocorrer em um sentido contrário, tal como na mudança por correção (tomamos a nomenclatura "mudança" por sinônimo de "recategorização") designada por Custódio Filho (2011), esta transformação opositiva não surte grandes efeitos impactantes ao leitor, como acontece na mudança por correção. (MATOS, 2018, p. 239).

Para exemplificar essas situações, a autora apresenta, entre outras, a seguinte nota jornalística, gênero discursivo sobre o qual se debruçou durante sua investigação:

Exemplo 2 - Recategorização por desconfirmação em nota jornalística

(98) Setenta mil doses de vacinas contra a febre amarela, vendidas pela Fiocruz, foram rejeitadas pelas autoridades sanitárias do Sudão. O produto chegou ao pais africano sem os lacres necessários para garantir sua conservação. O caso é o mais recente numa série de problemas relacionados à produção da fundação - cuja excelência histórica não se questiona. Funcionários do Complexo Tecnológico de Vacinas de Manguinhos informaram à coluna que os descartes de lotes por contaminação cresceram consideravelmente nos últimos tempos.

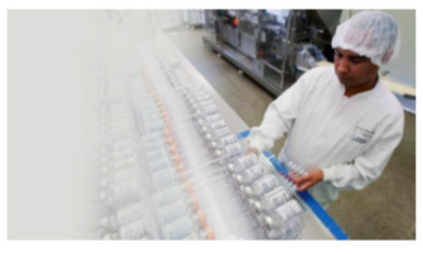

(Portal Isto é, por Ricardo Boechat, 03/06/2016)

Fonte: Matos (2018, p. 240).

No exemplo 2, conforme explica Matos (2018), a expressão em destaque redefine o referente Fiocruz de forma positiva. Essa recategorização é contrária à avaliação negativa que vinha sendo feita ao longo do texto por meio da locução verbal "foram rejeitadas", da anáfora indireta "(sem) o lacre necessário para garantir sua conversação" e do encapsulamento em "o caso" seguido do predicativo "mais recente numa série de problemas relacionados à produção da função". Essas informações orientam o leitor em sentido contrário à orientação argumentativa que se construiu no início do texto, o que configura, portanto, segundo Matos (2018), um caso de recategorização por desconfirmação.

Matos (2018) propõe, ainda, a noção de redes referenciais e defende que pode haver relações entre todos os referentes do texto na constituição de gêneros e das funções dessas associações na continuidade e nas transformações referenciais. Levantamos a hipótese de que essas 
conexões se estendem também aos hipergêneros, ou, como temos preferido nos referir neste artigo, aos compósitos de gêneros.

\section{Compósitos de gêneros na mídia Facebook}

Para ilustrar nossas reflexões teóricas, optamos por fazer uma observação de como o referente "Covid-19" é introduzido e retomado em postagem extraída do jornal O Povo, publicada em 17 de dezembro de 2020; em seguida, levando em consideração o compósito de gêneros no qual se insere essa interação digital on-line, analisaremos como esse referente é retomado e recategorizado nesse agrupamento. Essa análise nos permitirá perceber a que possibilidades de interpretação do referente o interlocutor é conduzido.

Com base em vídeo divulgado pelo jornal $0 \mathrm{PovO}^{4}$, em comemoração de seus 90 anos de circulação, menciona-se que o periódico foi fundado por Demócrito Rocha, homem que, segundo a escritora (e colaboradora do jornal) Rachel de Queiroz, tinha ideias liberais e simpatizava com o anarquismo. Nesse vídeo, o médico Marigelbio Lucena afirma que o jornal é extremamente "partidarizado com viúvas do socialismo de Dilma e Lula" e "de sectários e xiitas de esquerda". Ainda com base no material audiovisual divulgado pelo periódico, a jornalista Carla Pinto menciona que o jornal se vincula a "movimentos de esquerda, de trabalhadores", mas que também dá espaço a outros alinhamentos políticos. Em matéria divulgada no website do 0 Povo, os jornalistas mencionam que a publicação é voltada para "o agricultor, a mulher, os povos indígenas, a criança e o adolescente". Essas informações contextuais, relativas às ideologias que perpassam o conteúdo do jornal e também à descrição do público-alvo do periódico com o qual trabalharemos nesta análise, contribuem para que compreendamos o posicionamento político do jornal, o qual costuma apresentar críticas em relação às ações do governo bolsonarista.

A postagem do jornal se refere a um pronunciamento do atual presidente brasileiro Jair Bolsonaro em que este menciona que "nunca chamou Covid-19 de gripezinha". Esse acontecimento foi bastante discutido e teve alta repercussão, apresentando um número expressivo de comentários. No momento em que a cópia da tela foi feita, essa postagem apresentava 1,3 mil reações, as quais indicam, principalmente,

4 Vídeo disponível em matéria publicada em: https://especiais.opovo.com.br/acervo/2018/90an os/90anoshistorias.html. 
V. 11 (3)

$430-450$ set-dez 2021 consentimento, riso e raiva (representadas pelos emojis 셜망ㅇㅇ) por parte dos usuários. Conforme verificamos, havia 749 comentários e 269 compartilhamentos, o que sinaliza alta repercussão da notícia divulgada pelo jornal o Povo no compósito.

Neste recorte, optamos por utilizar a ferramenta de organização "Mais relevantes" e selecionamos os primeiros comentários. A mídia Facebook apresenta a opção de visualizar os comentários pelos "Mais relevantes" que, de acordo com as informações divulgadas pela própria mídia, mostra os "comentários de amigos e os comentários mais envolventes primeiro"; pelos "Mais recentes", que mostra "todos os comentários, com os mais recentes primeiro"; e por "Todos os comentários", que mostra "todos os comentários, incluindo possíveis spam. Os comentários mais relevantes aparecerão primeiro. Nossa preferência pela opção "Mais relevantes" vai ao encontro da abordagem de análise ecológica proposta por Paveau (2017). A linguista francesa propõe que os textos produzidos em ambiente digital on-line sejam analisados em uma perspectiva integrada ou simétrica, o que significa observar tanto aspectos linguageiros quanto tecnológicos. Nesse sentido, concordarmos em reconhecer o papel de aspectos técnicos, como a presença de algoritmos, na construção de sentido em ambientes digitais on-line e, por isso, optamos por observar a construção dos sentidos em função da organização de comentários feita por meio da ferramenta "Mais relevantes". 
Exemplo 1 - Cópia da tela de postagem de 27 de novembro de 2020 na página do Facebook do jornal O Povo e sequência de cópias de tela de GIF animado
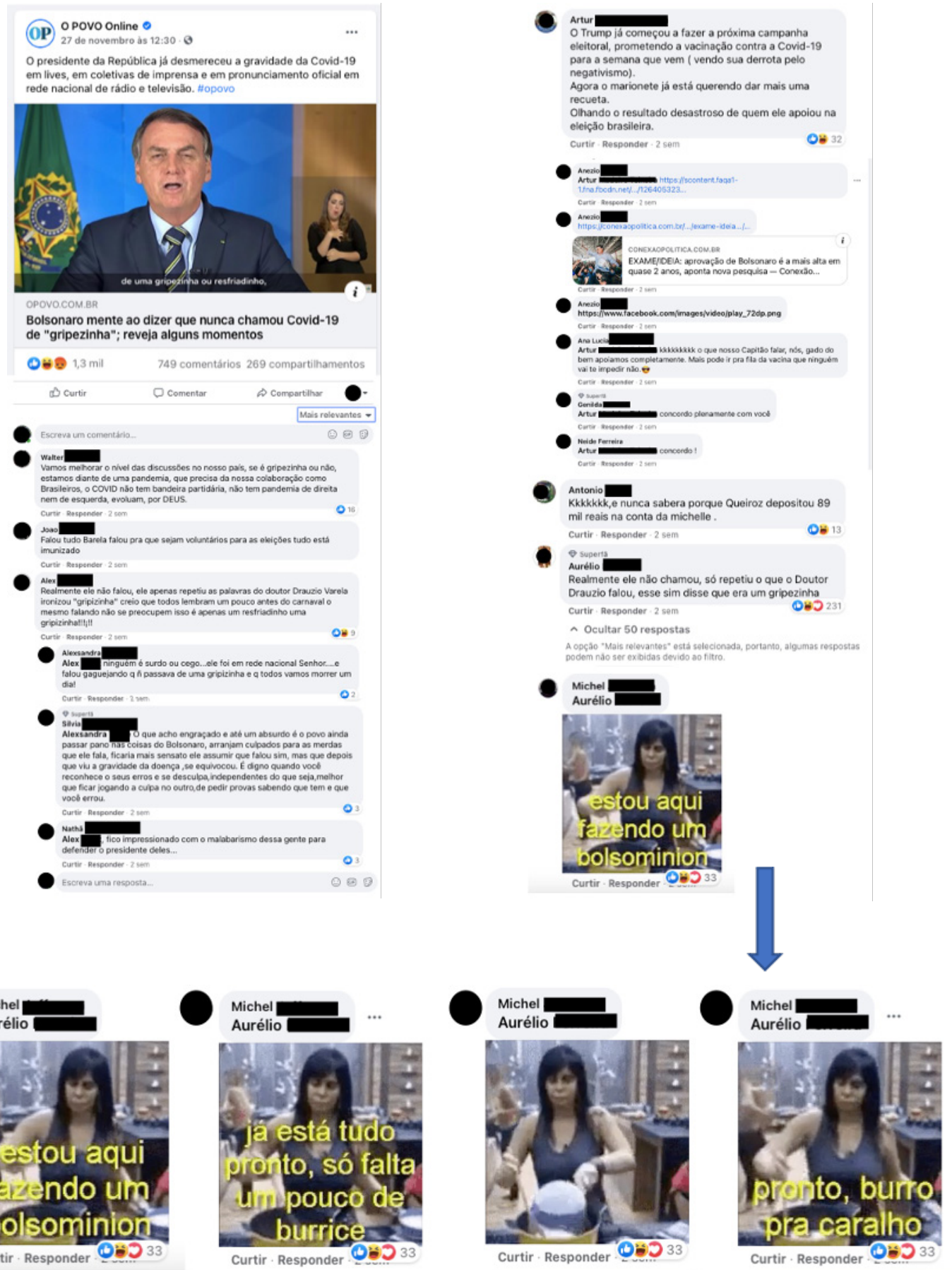

Fonte: Postagem no Facebook do jornal o Povo de 27 de novembro de $2020^{5}$.

Na nossa seleção de comentários, foi possível visualizar um GIF Animado, ou seja, uma composição de várias imagens em movimento como se fosse uma pequena animação. Com o objetivo de adaptarmos esse tipo de corpus às condições de produção deste artigo, optamos por inserir, na parte inferir do Exemplo 1, uma sequência de cópias de tela 
V. 11 (3)

$430-450$ set-dez 2021

do GIF Animado. Esse recurso nos permite ter uma ideia próxima do que seria a imagem em movimento. Ainda em relação à extração do corpus, salientamos que foram omitidas as fotografias dos perfis dos usuários para que sejam preservadas suas imagens individuais e mantidos apenas os primeiros nomes. Acreditamos que essas informações são essenciais para a compreensão integral dos textos e de como o referente "coronavírus" é construído nesse agrupamento.

Iniciamos considerando como o referente "coronavírus" é introduzido pelo jornal O Povo na postagem. Em cima da imagem do presidente Jair Bolsonaro, o referente é introduzido pela expressão nominal "Covid-19", o que pode contribuir para interpretar o referente a partir de uma perspectiva científica.

A cópia de tela do vídeo em que o presidente faz seu pronunciamento apresenta uma imagem estática deste e, mais à direita, da intérprete de Língua Brasileira de Sinais, seguida da legenda "de uma gripezinha ou resfriadinho". Nesse trecho, o jornal alude a pronunciamento realizado em 24 de março de 2020 , em que o presidente Bolsonaro se referiu ao vírus como uma "gripezinha", minimizando os riscos da pandemia. Com a menção à fala do presidente brasileiro na postagem, o referente "coronavírus" passa por um processo de transformação radical. Recategorizado pelos termos "gripezinha e resfriadinho", o referente passa a orientar os interlocutores para um sentido contrário ao que se vinha construindo pelo jornal. O uso dessas duas expressões nominais faz com que o referente "coronavírus" mude de estatuto, passando a ter um sentido mais brando, de doença com efeitos inofensivos.

Por outro lado, as reações de riso e raiva à postagem, representadas, respectivamente, pelos emojis 상 e (6), podem ser interpretadas como um deboche ou como uma reprovação à forma como o presidente se refere ao coronavírus, descredibilizando, portanto, essa visão amena dos efeitos da doença e também contribuindo para desconfimar esse traço implicado ao referente "COVID-19". Note-se que tais recursos de reação e de compartilhamento não compunham o texto original da nota, mas, quando ela é retextualizada para a versão on-line, para ser postada nesse espaço digital, passa a constituir um novo texto, no qual estão previstas as reações e os compartilhamentos. Além disso, esse texto é pensado para coabitar o espaço de outro(s) texto(s): os comentários, compondo com ele um compósito de gêneros. 
O primeiro comentário, de Walter, retoma o referente pelo uso do substantivo "COVID" e da expressão "se é gripezinha ou não, estamos diante de uma pandemia", indicando uma tentativa de relativizar a polêmica instalada pela evocação do tema, e, ao mesmo tempo, reconstruindo o referente, acrescentando a ideia de que o coronavírus é preocupante e que deve receber a atenção de todos os partidos políticos, alinhados ou não ao governo bolsonarista. O número significativo de reações a esse comentário (16 curtidas) pode demonstrar o consentimento dos interlocutores em relação à forma como o referente foi recategorizado por Walter.

No seu primeiro comentário, Alex retoma oreferente "gripizinha (sic)" e "resfriadinho" para defender o presidente e mencionar que, na realidade, Bolsonaro apenas repetiu termos utilizados por um médico conhecido nacionalmente: "ele apenas repetiu as palavras do doutor Drauzio Varela". Aqui, Alex colabora para a reelaboração do estatuto do referente, desta vez atribuindo os termos mencionados à fala de um profissional da saúde, o que, portanto, pode levar o interlocutor a legitimar a afirmação dita pelo presidente de considerar o coronavírus como um simples resfriado ${ }^{6}$. Tendo em vista essa fato, as reações de risada ao comentário podem indicar descrédito em relação à percepção apresentada por Alex, contribuindo, mais uma vez, para o jogo de mudança do estatuto do referente dentro das interações que se estabelecem no compósito de gêneros, e não apenas dentro de um só texto.

Com essas conclusões, queremos levantar a hipótese de que a noção de rede referencial não se restringe aos limites de um texto apenas, mas pode espraiar-se para as alusões feitas nas relações entre os textos do compósito de gêneros. Os referentes, como defende Matos (2018), atuam numa rede referencial, que pode, no exemplo analisado, ser percebida pelas inúmeras formas como "Bolsonaro" é retomado no compósito. Os opositores ao presidente brasileiro utilizam expressões, como "as merdas que ele fala" (comentário de Silvia), "o presidente deles" (comentário de Nathã), "marionete" (comentário de Artur), "bolsominion", "burrice" e "burro pra caralho" (no GIF animado que aparece no comentário de Michel). Esse GIF, inclusive, apresenta uma sequência de imagens da artista brasileira Gretchen

\footnotetext{
${ }^{6}$ Para entender a situação, é preciso que o interlocutor retome a polêmica em relação à descontextualização feita sobre um comentário emitido pelo médico Drauzio Varela antes de a crise sanitária ter chegado ao Brasil.
} 
V. 11 (3)

$430-450$ set-dez 2021

(cujos comentários públicos demonstram sua oposição ao presidente), conhecida por apresentar posicionamentos francos e bem-humorados. A artista costumeiramente tem sua imagem associada a postagens virais na internet. Por sua vez, os defensores de Jair Bolsonaro retomam o referente por meio de expressões, como "nosso Capitão", "gado do bem". Esse jogo de reelaboração do referente "Bolsonaro" entra em rede com o referente "coronavírus" e pode nos levar à seguinte trilha de sentidos: os que apoiam o presidente interpretam o referente como uma doença simples, como uma gripe qualquer; por outro lado, os opositores do presidente interpretam o referente como um vírus pandêmico, de consequências devastadoras. Essa dinâmica de re(elaborações) só pode ser percebida se levarmos em consideração o compósito de gêneros apresentado na página do Facebook do jornal o Povo.

\section{Considerações finais}

Como vimos, a construção referencial se torna mais complexa ainda quando, nos modos de interação digital on-line, observamos o compósito de gêneros que ali se atualiza. Neste artigo, buscamos mostrar que o referente "Covid-19" é introduzido e retomado, num processo de re(elaboração) complexo, que se dá num jogo de mudança e progressão referencial percebido tanto na postagem inicial feita pelo jornal quanto nos comentários e nas reações presentes em diferentes textos do compósito de gêneros.

$\mathrm{Na}$ postagem analisada, percebemos como o processo de recategorização do referente "coronavírus" mantém relações com a re(elaboração) do referente Bolsonaro, o que nos leva a perceber a importância de se analisar os referentes em rede dentro de um compósito de gêneros. Vimos também o papel desempenhado pelas reações (representadas por emojis) e pelos GIFs e como aspectos contextuais contribuem para observarmos a complexidade do fenômeno da referenciação. Com este trabalho, esperamos contribuir para a ampliação dos estudos em torno dessa categoria da LT em contextos digitais on-line.

\section{Referências Bibliográficas}

ADAM, J.-M. Textos: tipos e protótipos. Tradução de CAVALCANTE et al. São Paulo: Contexto, 2019.

BONINI, A. Mídia / suporte e hipergênero: os gêneros textuais e suas relações. 
RBLA, Belo Horizonte, v. 11, n. 3, p. 679-704, 2011. Disponível em: www. scielo.br/pdf/rbla/v11n3/05.pdf. Acesso em: dez. 2020.

CARVALHO, J. L. Q. Mídia, suporte e hipergênero: por uma análise crítica de blogs no ciberativismo. 2020. 96 f. (Projeto de Doutorado em Linguística) Programa de Pós-Graduação em Linguística, Universidade Federal do Ceará, Fortaleza, 28. out de 2020.

CAVALCANTE, M. M. CUSTÓDIO FILHO, V., BRITO, M. A. P. Coerência, referenciação e ensino. 1 ed. São Paulo: Cortez, 2014.

CAVALCANTE, M. M.; BRITO, M. A. P. O caráter naturalmente recategorizador das anáforas. In: AQUINO, Z. G. O.; GONÇALVES-SEGUNDO, P. R. (Orgs.). Estudos do discurso: caminhos e tendências [Internet]. São Paulo: Paulistana, 2016. Disponível em: http://cied.fflch.usp.br/sites/cied.fflch.usp.br/files/u31/ Livro-CIED-2016-final.pdf. Acesso em: dez. 2020.

CAVALCANTE, M. M.; MARTINS, M. A. Referenciação: em síntese. In: LIMA, A. H., SOARES, M. E., CAVALCANTE, S. A. de S. Linguística geral: os conceitos que todos precisam conhecer. São Paulo: Pimenta Cultural, 2020, v. 2, p. 237272. Disponível em: https://www.pimentacultural.com/linguistica-geral-2. Acesso em: dez. 2020.

CAVALCANTE, M. M. Referenciação: sobre coisas ditas e não ditas. Fortaleza: Edições UFC, 2011.

CAVALCANTE, Mônica Magalhães et al. O texto e suas propriedades: definindo perspectivas para análise. (Con)Textos Linguísticos - Linguística Textual e Análise da Conversação: conceitos e critérios de análise, Espírito Santo, v. 13, n. 25, p.25-39, set. 2019. Disponível em: http://periodicos.ufes.br/ contextoslinguisticos/article/view/27884/18764. Acesso em: dez. 2020.

CUSTÓDIO-FILHO, Valdinar. Múltiplos fatores, distintas interações: esmiuçando o caráter heterogêneo da referenciação. 331p. Tese (Doutorado em Linguística) - Universidade Federal do Ceará, Fortaleza, 2011.

LIMA, Silvana Maria Calixto. Entre os domínios da metáfora e da metonímia: um estudo de processos de recategorização. Tese (Doutorado em Linguística) - Universidade Federal do Ceará, Fortaleza, 2009.

LIMA. Sóstenes Cezar de. Hipergênero: agrupamento ordenado de gêneros na constituição de um macroenunciado. Tese (Doutorado em Linguistica) Universidade de Brasília, p. 273. 2013.

MARCUSCHI, Luiz Antônio. Produção textual, análise de gêneros e compreensão. São Paulo: Parábola Editorial, 2008.

MATOS, Janaica Gomes. As redes referenciais na construção de notas jornalísticas. 259 p. Tese (Doutorado em Linguística) - Universidade Federal do Ceará, Fortaleza, 2018.

MONDADA, Lorenza; DUBOIS, Daniele. Construção de objetos de discurso e categorização: uma abordagem dos processos de referenciação. In: CAVALCANTE et al. (Org.). Referenciação. São Paulo: Contexto, 2003. p. 1752. 
v. 11 (3)

$430-450$

set-dez 2021

NASCIMENTO, Suelene Silva Oliveira. A construção multimodal dos referentes em textos verbo-audiovisuais. 149f. Tese (Doutorado em Linguística) Universidade Federal do Ceará, Fortaleza, 2014.

PAVEAU, Marie-Anne. L'Analyse du Discours Numérique. Dictionnaire des formeset des pratiques. Paris: Hermann Éditeurs, 2017.

SIMAS, Fábio Macedo. Referenciação em fóruns educacionais em EAD: a interface entre oralidade e escrita. 2015. 285 f. Tese (Doutorado) - Curso de Estudos de Linguagem, Instituto de Letras, Universidade Federal Fluminense, Niterói, 2015. Disponível em: http://bdtd.ibict.br/vufind/Record/UFF-2 b2e1cf065c2736ffc6b8be46f3756540. Acesso em: dez. 2020. 